\title{
Common mental illness in people with sensory impairment: results from the 2014 adult psychiatric morbidity survey
}

\author{
Natalie Shoham, Gemma Lewis, Sally McManus and Claudia Cooper
}

\section{Background}

People with sensory impairments may be at increased risk of depression and anxiety but experience barriers to accessing treatment.

\section{Aims \\ To investigate whether people with sensory impairment have more depressive and anxiety symptoms than people without, whether this is mediated by social functioning and whether they report greater non-treatment.}

\section{Method}

We analysed data from the English 2014 Adult Psychiatric Morbidity Survey using regression models, with the Clinical Interview Schedule-Revised (CIS-R) score as the primary outcome and self-reported hearing and vision impairment as exposures. A secondary outcome was self-reported receipt of mental health diagnosis and treatment. We used structural equation modelling to assess for mediation by social functioning.

\section{Results}

A total of $19.0 \%$ of people with hearing impairment, and $30.9 \%$ and $24.5 \%$ with distance and near visual impairments, respectively, had clinically significant psychological morbidity. Adjusted mean CIS-R score was 1.86 points higher in people with hearing impairment compared with those without $(95 \% \mathrm{Cl} 1.30-2.42$, $P<0.001$ ). People with distance and near vision impairment had mean CIS-R scores 3.61 (95\% Cl 2.58-4.63, $P<0.001$ ) and 2.74
(95\% $\mathrm{Cl} 2.12-3.37, P<0.001)$ points higher, respectively, than those without. Social functioning accounted for approximately $50 \%$ of these relationships between sensory impairment and psychological morbidity. We found no evidence of an increased treatment gap for people with sensory impairment.

\section{Conclusions}

Social functioning, a potentially modifiable target, may mediate an association between sensory impairment and depressive and anxiety symptoms

\section{Declaration of interest \\ None.}

Keywords

Social functioning; sensory impairment; depression; anxiety disorders; epidemiology.

\section{Copyright and usage}

(c) The Author(s) 2019. This is an Open Access article, distributed under the terms of the Creative Commons AttributionNonCommercial-NoDerivatives licence (http://creativecommons.org/licenses/by-nc-nd/4.0/), which permits non-commercial re-use, distribution, and reproduction in any medium, provided the original work is unaltered and is properly cited. The written permission of Cambridge University Press must be obtained for commercial re-use or in order to create a derivative work.

\section{Background}

Hearing impairment affects 11 million people in the UK. ${ }^{1}$ Most have acquired hearing impairment, which predominantly affects older people. ${ }^{1}$ A minority experience pre-lingual deafness, with onset of severe or profound hearing impairment before speech development. There is evidence that people with hearing impairment have elevated rates of common mental illness (depressive and anxiety disorders), ${ }^{2-5}$ but not all studies have found this association. ${ }^{6,7}$ Variable sample sizes, outcome measures and study populations probably explain these conflicting findings. ${ }^{6,8}$ Severe visual impairment affects more than 2 million people in the UK and like hearing impairment, predominantly occurs in older people. ${ }^{9}$ The prevalence of depression among visually impaired adults has been reported to be higher than in comparable populations without visual impairment in most studies, ${ }^{4,10}$ although one prospective cohort study found that a deterioration in near vision did not increase the risk after controlling for confounders. ${ }^{11}$

Understanding of the mechanisms behind possible associations between sensory impairment and common mental illness is limited. ${ }^{12,13}$ Being unable to hear conversations, or see facial expressions, can present significant obstacles to accessing social support and connection. People with sensory impairment have reported experiencing barriers to going out, reduced friendship networks and higher rates of loneliness and social isolation. ${ }^{1,7,9}$ Reduced social support has been associated with depression and anxiety. ${ }^{8}$
Social functioning can be determined by social opportunities and is one way of describing interactions with other people, the environment and the community.

Barriers to access to mental healthcare have been described; $15-30 \%$ of pre-lingually deaf people have reported avoiding booking appointments. ${ }^{14,15}$ Cited reasons include reliance on telephone booking and lack of funding for sign language interpreters. ${ }^{14,15}$ A large US study found that people with acquired hearing impairment also experienced barriers to accessing treatment. ${ }^{16}$ Similarly, people with visual impairment can experience problems because of providers giving only written information, or inadequate transport provision for appointments. ${ }^{17}$ We hypothesised that because of difficulties accessing treatment, people with sensory impairment might live with common mental illness for longer; that is have a larger 'treatment gap'.

It is important to understand whether people with sensory impairment are at increased risk of depression and anxiety, and if so, what mediates this, in order to inform strategies for identifying and intervening to ameliorate these symptoms, and mental health service planning. This is the first national survey comparing prevalence of symptoms, diagnoses and treatments for common mental disorders in people with and without sensory impairment; and to explore social functioning as a possible mediator of the relationship between sensory impairment and mental illness. 


\section{Aims}

We tested our primary hypotheses that (a) people with sensory impairments have more symptoms of common mental disorder than people without; and (b) after adjusting for level of symptoms, they are less likely to have received a formal diagnosis or treatment. Our secondary hypothesis was that the association between sensory impairment and common mental illness is partly accounted for by reduced social functioning.

\section{Method}

We analysed cross-sectional data from the 2014 Adult Psychiatric Morbidity Survey (APMS).

\section{Participants and procedures}

The 2014 APMS is a sample of residents aged 16 and over living in private households in England. ${ }^{18}$ Sampling was multistage and designed to produce a sample representative of the national population. At stage 1 postcode sectors were stratified before being chosen at random. Households were then randomly selected from within each chosen postcode sector. Finally, one individual from each selected household was randomly identified to participate. Data are weighted to account for selection probability and nonresponse. Our study is based on phase 1 data, which was collected by lay interviewers. Permission to use the data in our study was granted by NHS Digital. Further details on the APMS methodology and sampling strategy are available elsewhere. ${ }^{18}$

\section{Measures}

\section{Outcome measures}

The Clinical Interview Schedule-Revised (CIS-R) is a measure of common mental disorders that corresponds to the ICD-10, which is highly reliable and valid. ${ }^{19}$ The total score, which ranges from 0 to 57 , indicates the level of common mental illness symptoms. The CIS-R was used to assess for symptoms of depression, anxiety, phobias and obsessive-compulsive disorder. The total CIS-R score was our primary outcome. In addition, a standard cut-off of 12 and above was used to analyse presence or absence of clinically significant symptoms of common mental illness as a binary variable. ${ }^{18}$

A secondary outcome was being in receipt of a psychiatric diagnosis or treatment within the past year. APMS participants were shown cards listing diagnoses, psychotropic medications and psychological conditions. They were asked, 'Did a doctor, psychiatrist or other professional tell you that you had [any of this list of conditions]?' to decide whether a psychiatric diagnosis had been received; they were also asked whether they had been prescribed any of the psychotropic medications listed on cards shown to them. Interviewers checked the packaging of medications to ensure correct identification. To decide if participants had received psychological therapy, they were shown a card listing psychological therapies and asked; 'Are you currently having any counselling or therapy listed on this card for a mental, nervous or emotional problem?'

\section{Exposure variables}

Participants were asked whether they had hearing impairment or wore a hearing aid; those that gave an affirmative response were recorded as having a hearing impairment. Presence of distance vision impairment was determined by asking participants whether they had any difficulty seeing a face across the room even with visual aids; and presence of near vision impairment by asking whether they had difficulty reading a newspaper even with visual aids. Participants gave their answers as a degree of difficulty (no difficulty, mild difficulty, moderate difficulty, severe difficulty, cannot do). We analysed this data as binary (having difficulty of any severity or not).

\section{Potential confounders measured}

We recorded socioeconomic, health and health behaviour covariates that might be linked to the outcome (gender, ethnicity, age in 10 -year brackets, employment type, history of significant physical health condition, household composition, marital status, verbal IQ as measured by the National Adult Reading Test, ${ }^{20}$ history of smoking and Alcohol Use Disorders Identification Test $(\text { AUDIT) })^{21}$ score). A physical health condition that could confound results was coded as present if the participant reported having had cancer, stroke, high blood pressure, heart attack or angina, diabetes, epilepsy, migraine or frequent headaches, dementia or Alzheimer's or another nervous system disorder since the age of 16 .

\section{Potential mediators measured}

The Social Functioning Questionnaire (SFQ) is a validated measure of perceived social functioning. ${ }^{22}$ It is an eight-item scale with a score range from 0 to 24 , with higher scores indicating lower social functioning. Topics covered include feelings of loneliness, stress, relationships and enjoyment of leisure time.

\section{Statistical analysis}

All analyses were performed using Stata version 14.2. ${ }^{23}$ Where participants answered 'don't know' or 'not applicable' or refused to answer a question, this data was treated as missing. The weighting used in the original APMS survey design was preserved in our study to keep the sample as representative as possible of the national population, when the full sample was used. We report weighted percentages but unweighted absolute numbers.

We assessed the association between presence of sensory impairment and CIS-R score using a series of regression models. We used two outcome variables: total CIS-R score and whether the CIS-R score was 12 or above. The three exposure variables were presence of hearing impairment, presence of near vision impairment and presence of distance vision impairment. Influence of sensory impairment on total CIS-R score was assessed using linear regression. The odds of having a CIS-R score of 12 or above for people with sensory impairment relative to those without were calculated using logistic regression, 95\% CIs are presented throughout. We also ran sensitivity analyses including only participants aged under 65 or 65 and above, to see whether there was a different relationship between sensory impairment on CIS-R score in older and younger people.

To assess the odds of receiving treatment for people with sensory impairment relative to those without, we conducted logistic regressions adjusting for total CIS-R score. We assessed three selfreported outcome variables: receipt of a psychiatric diagnosis, receipt of medical treatment and receipt of psychological treatment. We used the same three exposure variables as in our previous models. We ran a sensitivity analysis including only people who had a CIS-R score typically considered high enough to warrant treatment (18 or greater).

To test for mediation, we checked whether putative mediators were associated with both the exposure variables and outcome variable (CIS-R score); an essential criterion for mediation. We then employed structural equation modelling using the sem command in Stata. ${ }^{23}$ We estimated the degree of mediation by dividing the coefficient of the adjusted indirect effect of sensory impairment on CIS-R score (via the potential mediator) by the adjusted coefficient of the total effect of sensory impairment on CIS-R score. 


\begin{tabular}{|c|c|c|c|}
\hline Characteristic & Overall & No hearing impairment & Hearing impairment \\
\hline Total, $n$ (weighted \%) & $7488(99.3)$ & $6177(85.3)$ & $1311(14.7)$ \\
\hline Male, $n$ (weighted \%) & $3036(48.9)$ & $2385(47.6)$ & $651(56.0)$ \\
\hline \multicolumn{4}{|l|}{ Age, $n$ (weighted \%) } \\
\hline $16-24$ & $557(14.1)$ & $526(15.7)$ & $31(5.1)$ \\
\hline $25-34$ & $1029(16.9)$ & $973(18.8)$ & $56(5.8)$ \\
\hline $35-44$ & $1170(16.1)$ & $1068(17.3)$ & $102(9.5)$ \\
\hline $45-54$ & $1285(17.4)$ & $1172(18.6)$ & $113(10.3)$ \\
\hline $55-64$ & 1206 (13.8) & $983(13.0)$ & $223(18.1)$ \\
\hline $65-74$ & 1185 (11.8) & $856(10.0)$ & $329(22.3)$ \\
\hline $75+$ & $1056(10.0)$ & $599(6.7)$ & $457(29.0)$ \\
\hline \multicolumn{4}{|l|}{ Ethnicity, $n$ (weighted \%) } \\
\hline White British & $6364(80.7)$ & $5157(79.2)$ & $1207(89.6)$ \\
\hline White other & $425(6.7)$ & $380(7.1)$ & $45(4.2)$ \\
\hline Black/African/Caribbean/Black British & $196(3.1)$ & $185(3.5)$ & $11(1.1)$ \\
\hline Asian/Asian British & $353(6.9)$ & $316(7.4)$ & $37(4.1)$ \\
\hline Mixed/other & $150(2.6)$ & $139(2.9)$ & $11(1.0)$ \\
\hline \multicolumn{4}{|l|}{ Marital status, $n$ (weighted \%) } \\
\hline Married or cohabiting & $4111(61.7)$ & $3428(61.3)$ & $683(64.1)$ \\
\hline Single & $1570(24.3)$ & $1420(26.4)$ & $150(12.0)$ \\
\hline Widowed, divorced or separated & $1807(14.0)$ & 1329 (12.2) & $478(23.9)$ \\
\hline \multicolumn{4}{|l|}{ Household composition, $n$ (weighted \%) } \\
\hline 1 adult aged $16-59$, no children & $887(7.1)$ & $791(7.4)$ & $96(5.2)$ \\
\hline 2 adults aged $16-59$, no children & $1320(19.8)$ & $1193(21.1)$ & $127(12.6)$ \\
\hline Small family & $1226(15.8)$ & $1146(17.4)$ & $80(6.7)$ \\
\hline Large family & $337(5.6)$ & $315(6.2)$ & $22(2.6)$ \\
\hline Large adult household & $1036(26.4)$ & $929(28.1)$ & $107(16.8)$ \\
\hline 2 adults, 1 or both aged $60+$, no children & $1397(16.9)$ & 948 (13.4) & $449(37.1)$ \\
\hline 1 adult, aged $60+$, no children & $1285(8.3)$ & $855(6.5)$ & 430 (19.1) \\
\hline \multicolumn{4}{|l|}{ Tenure, $n$ (weighted \%) } \\
\hline Owner-occupier & $4904(63.8)$ & 3979 (62.5) & $925(71.2)$ \\
\hline Social renter & 1265 (15.9) & $1018(15.8)$ & $247(16.5)$ \\
\hline Private or other renter & $1294(19.9)$ & $1159(21.3)$ & $135(11.9)$ \\
\hline \multicolumn{4}{|l|}{ Employment type, $n$ (weighted \%) } \\
\hline Managerial/professional & $1791(26.0)$ & $1633(27.8)$ & $158(15.0)$ \\
\hline Intermediate & $678(9.2)$ & $621(9.9)$ & $57(5.2)$ \\
\hline Small employers/own account workers & $426(6.3)$ & $371(6.5)$ & $55(5.1)$ \\
\hline Lower supervisory/technical & 205 (3.3) & $181(3.5)$ & $24(2.2)$ \\
\hline Semi-routine/routine & $1137(18.3)$ & $1014(19.4)$ & $123(12.1)$ \\
\hline Never worked/not worked in past year & $2935(30.8)$ & $2087(26.3)$ & $848(56.8)$ \\
\hline Not classified for another reason & $316(6.2)$ & $270(6.6)$ & $46(3.6)$ \\
\hline \multicolumn{4}{|l|}{ Physical health condition, ${ }^{\mathrm{b}} \mathrm{n}$ (weighted \%) } \\
\hline Yes & $3610(42.6)$ & $2758(39.5)$ & $852(60.5)$ \\
\hline No & $3878(57.4)$ & $3419(60.5)$ & 459 (39.5) \\
\hline \multicolumn{4}{|l|}{ Ever smoked cigarette, $n$ (weighted \%) } \\
\hline Yes & $4629(60.7)$ & $3753(59.6)$ & 876 (67.5) \\
\hline No & 2859 (39.3) & $2424(40.4)$ & 435 (32.5) \\
\hline Alcohol Use Disorders Identification Test score, mean (s.d.) & $4.1(4.5)$ & $4.2(4.6)$ & $3.7(4.2)$ \\
\hline Verbal IQ, mean (s.d.) & $103.1(15.6)$ & $103.2(15.4)$ & $102.5(16.4)$ \\
\hline Social Functioning Questionnaire score, mean (s.d.) & $4.1(3.5)$ & $4.2(3.5)$ & 3.9 (3.4) \\
\hline Clinical Interview Schedule Revised score, mean (s.d.) & $5.5(7.7)$ & $5.4(7.7)$ & $6.0(7.7)$ \\
\hline
\end{tabular}

All of the above analyses were carried out in stages: as univariate models based on the analytic sample, and as multivariate models to adjust for potential confounders. We excluded socioeconomic covariates from regression models if they were not theoretically plausible confounders or did not show evidence of association with both sensory impairment and CIS-R score and effect on the relationship between these variables.

\section{Results}

In total, 7546 people participated in the APMS 2014 survey and completed the CIS-R. The overall response rate was $57 \%$. There were 7488 people who had given information on all relevant exposures, primary outcomes and confounding variables and could be included as the analytic sample. The mean CIS-R score in this sample was $5.52($ s.d. $=7.67)$. There were $1220(15.7 \%)$ people who had a clinically significant score of 12 or above. A total of 1311 (14.7\%) people reported hearing impairment, 441 (5.1\%) people reported distance vision impairment and 872 (10.4\%) reported near vision impairment.

Tables 1 and 2 show the characteristics of the analytic sample. Of note, people with sensory impairment were more likely to be aged over 65 , divorced or widowed, to live in social housing and to be economically inactive than people without. They were also more likely to have physical comorbidities and to smoke. 
Table 2 Relationship of characteristics of analytic sample to visual impairment ${ }^{\mathrm{a}}$

\begin{tabular}{|c|c|c|c|c|}
\hline Demographic variable & $\begin{array}{l}\text { No distance vision } \\
\text { impairment }\end{array}$ & $\begin{array}{l}\text { Distance vision } \\
\text { impairment }\end{array}$ & $\begin{array}{l}\text { No near vision } \\
\text { impairment }\end{array}$ & $\begin{array}{l}\text { Near vision } \\
\text { impairment }\end{array}$ \\
\hline Total, $n$ (weighted \%) & 7047 (94.9) & $441(5.1)$ & $6616(89.6)$ & $872(10.4)$ \\
\hline Male, $n$ (weighted \%) & $2873(49.2)$ & $163(43.4)$ & $2685(48.9)$ & 351 (48.5) \\
\hline \multicolumn{5}{|l|}{ Age, $n$ (weighted \%) } \\
\hline $16-24$ & 535 (14.3) & $22(10.9)$ & $522(14.7)$ & $35(9.0)$ \\
\hline $25-34$ & $991(17.1)$ & $38(12.4)$ & $981(17.9)$ & $48(8.5)$ \\
\hline $35-44$ & $1133(16.6)$ & $37(8.4)$ & $1101(17.0)$ & $69(8.8)$ \\
\hline $45-54$ & $1229(17.6)$ & 56 (13.3) & $1094(16.6)$ & $191(24.1)$ \\
\hline $55-64$ & $1132(13.6)$ & $74(16.3)$ & $1066(13.7)$ & $140(14.4)$ \\
\hline $65-74$ & $1105(12.0)$ & $80(15.1)$ & $1039(11.5)$ & $146(13.7)$ \\
\hline $75+$ & $922(9.2)$ & 134 (23.6) & $813(8.6)$ & $243(21.6)$ \\
\hline \multicolumn{5}{|l|}{ Ethnicity, $n$ (weighted \%) } \\
\hline White British & $5977(80.6)$ & 387 (83.4) & $5595(80.3)$ & $769(84.0)$ \\
\hline White other & $406(6.8)$ & $19(5.2)$ & $387(6.8)$ & $38(5.2)$ \\
\hline Black/African/Caribbean/ Black British & $184(3.0)$ & $12(4.3)$ & $179(3.1)$ & $17(2.9)$ \\
\hline Asian/Asian British & $342(7.1)$ & $11(3.1)$ & $321(7.1)$ & $32(5.0)$ \\
\hline Mixed/other & $138(2.5)$ & $12(4.0)$ & $134(2.6)$ & $16(2.8)$ \\
\hline \multicolumn{5}{|l|}{ Marital status, $n$ (weighted \%) } \\
\hline Married or cohabiting & 3929 (62.3) & $182(50.9)$ & 3428 (61.3) & $683(64.1)$ \\
\hline Single & $1480(24.3)$ & $90(23.7)$ & $1420(26.4)$ & $150(12.0)$ \\
\hline Widowed, divorced or separated & $1638(13.3)$ & $169(25.5)$ & 1329 (12.2) & 478 (23.9) \\
\hline \multicolumn{5}{|l|}{ Household composition, $n$ (weighted \%) } \\
\hline 1 adult aged $16-59$, no children & $834(7.0)$ & $53(8.8)$ & $773(7.0)$ & $114(8.2)$ \\
\hline 2 adults aged $16-59$, no children & $1268(20.1)$ & $52(14.8)$ & $1214(20.4)$ & $106(14.7)$ \\
\hline Small family & $1186(16.2)$ & $40(8.8)$ & $1149(16.8)$ & $77(7.7)$ \\
\hline Large family & $324(5.7)$ & $13(5.0)$ & $309(5.7)$ & $28(4.9)$ \\
\hline Large adult household & $992(26.7)$ & $44(21.1)$ & $914(26.2)$ & $122(28.0)$ \\
\hline 2 adults, 1 or both aged $60+$, no children & $1305(16.6)$ & $92(22.3)$ & $1225(16.5)$ & $172(20.4)$ \\
\hline 1 adult, aged 60+, no children & $1138(7.8)$ & $147(19.2)$ & $1032(7.4)$ & $253(16.2)$ \\
\hline \multicolumn{5}{|l|}{ Tenure, $n$ (weighted \%) } \\
\hline Owner-occupier & $4653(64.3)$ & $251(53.4)$ & $4392(64.5)$ & $512(57.4)$ \\
\hline Social renter & $1140(15.2)$ & $125(29.7)$ & $1020(14.6)$ & $245(27.1)$ \\
\hline Private or other renter & $1232(20.1)$ & $62(16.4)$ & $1184(20.5)$ & $110(15.0)$ \\
\hline \multicolumn{5}{|l|}{ Employment type, $n$ (weighted \%) } \\
\hline Managerial/professional & $1740(26.7)$ & $51(12.9)$ & $1686(27.4)$ & $105(13.3)$ \\
\hline Intermediate & 651 (9.3) & $27(6.7)$ & $622(9.4)$ & $56(7.6)$ \\
\hline Small employers and own account workers & $414(6.5)$ & $12(2.6)$ & $393(6.5)$ & $33(4.7)$ \\
\hline Lower supervisory/technical & $200(3.5)$ & $5(1.1)$ & $183(3.4)$ & $22(2.8)$ \\
\hline Semi-routine/routine & $1098(18.6)$ & $39(11.9)$ & $1032(18.7)$ & $105(14.4)$ \\
\hline Never worked/not worked in past year & $2656(29.4)$ & $279(56.2)$ & $2431(28.6)$ & $504(49.7)$ \\
\hline Not classified for another reason & $288(6.1)$ & $28(8.6)$ & $269(6.0)$ & $47(7.5)$ \\
\hline \multicolumn{5}{|l|}{ Physical health comorbidities, ${ }^{\mathrm{b}} \mathrm{n}$ (weighted \%) } \\
\hline Yes & 3308 (41.4) & $302(65.2)$ & 3064 (40.8) & $546(58.9)$ \\
\hline No & $3739(58.6)$ & $139(34.8)$ & $3552(59.3)$ & $326(41.2)$ \\
\hline \multicolumn{5}{|l|}{ Ever smoked cigarette, $n$ (weighted \%) } \\
\hline Yes & $4328(60.4)$ & $301(66.3)$ & $4037(60.0)$ & $592(66.7)$ \\
\hline No & $2719(39.6)$ & $140(33.7)$ & $2579(40.0)$ & $280(33.3)$ \\
\hline $\begin{array}{l}\text { Alcohol Use Disorders Identification Test score, mean } \\
\text { (s.d.) }\end{array}$ & $4.1(4.4)$ & $4.1(5.9)$ & $4.1(4.4)$ & $3.9(5.4)$ \\
\hline Verbal IQ, mean (s.d.) & $103.4(15.3)$ & $98.5(18.3)$ & $103.6(15.2)$ & $99.5(17.5)$ \\
\hline Social Functioning Questionnaire score, mean (s.d.) & $4.1(3.5)$ & $5.5(4.4)$ & $4.0(3.4)$ & $5.1(4.1)$ \\
\hline Clinical Interview Schedule Revised score, mean (s.d.) & $5.3(7.4)$ & $9.0(10.1)$ & $5.1(7.3)$ & $8.5(9.7)$ \\
\hline
\end{tabular}

\section{Association of anxiety and depressive symptoms with sensory impairments}

Results are presented in Tables 3 and 4 . Analyses were all adjusted for age, gender, ethnicity, type of employment, ever having smoked and history of significant physical health condition. ${ }^{24}$ Adjusted mean CIS-R score was 1.86 points higher in hearingimpaired compared with non-hearing-impaired people (95\% CI $1.30-2.42, P<0.001)$. People reporting distance and near vision impairments had higher adjusted mean CIS-R scores compared with those not reporting these impairments; by 3.61 points ( $95 \%$
CI 2.58-4.63, $P<0.001$ ) and 2.74 points (95\% CI 2.12-3.37, $P<0.001)$, respectively.

The odds of having a clinically significant CIS-R score (12 or more) were higher in all groups with sensory impairment, with the odds being over twofold for distance vision impairment (adjusted odds ratio $(\mathrm{AOR})=2.37,95 \%$ CI 1.79-3.13, $P<0.001$ ). For hearing impairment, the odds ratio was 1.83 (95\% CI $1.50-$ 2.24, $P<0.001)$ and for near vision impairment it was $1.83(95 \%$ CI 1.49-2.25, $P<0.001)$. Unadjusted results were similar, although the relationship between hearing impairment and CIS-R score was negatively confounded by age. 
Table 3 Influence of sensory impairment on total Clinical Interview

Schedule Revised (CIS-R) score

Mean difference in CIS-R score in

Model $n=7488$ sensory impairment $(95 \% \mathrm{Cl})$

Hearing impairment

Unadjusted analysis

Adjusted analysis ${ }^{a}$

$1.06(0.53-1.60)$

$1.86(1.30-2.42)$

Distance vision

impairment

Unadjusted analysis

Adjusted analysis ${ }^{a}$

Near vision impairment

Unadjusted analysis

Adjusted analysis ${ }^{a}$

$4.20(3.12-5.27)$

$3.61(2.58-4.63)$

$<0.001$

$<0.001$

$3.05(2.41-3.69)$

$<0.001$

$2.74(2.12-3.37)$

$<0.001$

a. Adjusted for age, gender, ethnicity, employment type, history of significant physical health condition and ever having smoked.

\section{Stratification by age}

Upon analysing older and younger participants separately, we found that the mean difference in CIS-R score between those with and without sensory impairment was greater in people aged under 65 . Following adjustment, it was 2.43 points (95\% CI 1.72-3.15, $P<0.001)$ in hearing impairment, 4.05 points $(95 \%$ CI $3.00-5.10$, $P<0.001)$ in distance vision impairment and 3.95 points $(95 \% \mathrm{CI}$ $3.20-4.69, P<0.001)$ in near vision impairment. By comparison for people aged 65 and over, the mean CIS-R score difference was 0.85 points ( $95 \%$ CI $0.37-1.32, P<0.001$ ) in hearing impairment, 2.65 (95\% CI 1.90-3.40, $P<0.001$ ) in distance vision impairment and 2.30 points $(95 \%$ CI $1.72-2.89, P<0.001)$ points in near vision impairment.

\section{Odds of receiving treatment}

Table 5 shows the results of these analyses. People with each of the three types of sensory impairment had increased odds of having received a diagnosis of mental illness relative to people without, following adjustment for CIS-R score, age, gender, ethnicity, employment type, history of significant physical condition and ever having smoked. There was no evidence that people with sensory impairment were any more or less likely to have received psychological therapy than people without. There was weak evidence that people with hearing impairment were more likely to have received medication, but no evidence of a difference in visual impairment following adjustment. A sensitivity analysis restricted to participants with a CIS-R score of 18 or above found no statistical evidence of a difference in rates of reported receipt of diagnosis, medication or psychotherapy in people with any kind of sensory impairment following adjustment (see supplementary Table 1; available at https://doi.org/10.1192/bjo.2019.81)

\section{Mediation}

Table 6 shows the different pathways in the mediation analysis for SFQ score. Following adjustment, SFQ score was strongly associated with CIS-R score, hearing impairment and both distance and near vision impairment, and therefore met essential criteria for mediation. For hearing impairment, distance vision impairment and near vision impairment 47.3\% (95\% CI 27.3-67.3\%, $P<0.001$ ), 54.9\% (97\% CI 40.8-69.0\%, $P<0.001)$ and 50.3\% (95\% CI 39.5-61.1\%, $P<0.001)$, respectively of the association between sensory impairment and CIS-R score appeared to be mediated by social functioning.

\section{Discussion}

We found evidence that the level of common mental illness symptomatology is higher, on average, in people with sensory impairment than people without. The odds of having a clinically significant level of symptoms was also increased, especially in distance vision impairment where they were over twice as high. This may explain why one cohort study found an association with common mental illness for distance but not near vision. ${ }^{11}$ We found that $19.0 \%$ of people with hearing impairment, $30.9 \%$ with visual impairment and $24.5 \%$ with near vision impairment had a clinically significant CIS-R score. These findings are in keeping with multiple previous studies, which have found that both hearing and visual impairment are associated with depressive and anxiety symptomatology. ${ }^{4,13,25-28}$ Our finding that the difference in CIS-R score is greater in younger people might reflect the fact that younger people with sensory impairment are more likely to be different to their peers in this regard, and to miss out on opportunities throughout life. ${ }^{29}$

It appears from our results that the association between all types of sensory impairment and common mental illness might be partially accounted for by self-perceived social functioning. This finding is consistent with research showing that older adults with hearing impairment are more likely to withdraw from social contact ${ }^{30}$ and that social isolation causing depression may be on the pathway from hearing impairment to cognitive decline according to cross-sectional findings. ${ }^{31}$ There is recent evidence that communication ability might determine a sense of social self-efficacy that mediates the pathway from hearing impairment to depression. ${ }^{32}$ There is also evidence linking visual impairment to loneliness. ${ }^{33}$ To our knowledge, ours is the first study to test social functioning as a mediator of the association between sensory impairment and common mental illness in a national survey sample.

The finding that people with sensory impairment were more likely to have received a diagnosis for common mental illness than people without runs counter to our second hypothesis. This is also unexpected in light of existing literature; it has previously been estimated that only $2 \%$ of deaf adults ever receive mental

\begin{tabular}{|c|c|c|c|c|}
\hline \multirow[b]{2}{*}{ Analytic sample ( $n=1220$ of $7488,15.7 \%)$} & \multicolumn{2}{|c|}{ Unadjusted analysis } & \multicolumn{2}{|c|}{ Adjusted analysis $^{a}$} \\
\hline & Odds ratio $(95 \% \mathrm{Cl})$ & $P$ & Odds ratio $(95 \% \mathrm{Cl})$ & $P$ \\
\hline Hearing impairment & & & & \\
\hline $\begin{array}{l}\text { Hearing impairment ( } n=237,19.0 \%) \text { versus no hearing impairment }(n=983,15.1 \%) \\
\text { Distance vision impairment }\end{array}$ & $1.32(1.11-1.58)$ & 0.002 & $1.83(1.50-2.24)$ & $<0.001$ \\
\hline $\begin{array}{l}\text { Distance vision impairment }(n=133,30.9 \%) \text { versus no distance vision impairment } \\
\qquad(n=1087,14.9 \%)\end{array}$ & $2.56(2.00-3.29)$ & $<0.001$ & $2.37(1.79-3.13)$ & $<0.001$ \\
\hline Near vision impairment & & & & \\
\hline Near vision impairment $n=233(24.5 \%)$ versus no near vision impairment ( $n=987(14.7 \%)$ & $1.89(1.57-2.26)$ & $<0.001$ & $1.83(1.49-2.25)$ & $<0.001$ \\
\hline
\end{tabular}


Table 5 Odds of receiving clinical intervention for people with sensory impairment relative to those without sensory impairment

Analytic sample $(n=7461)$

Unadjusted

analysis, odds ratio $(95 \% \mathrm{Cl})$

Adjusted

analysis, ${ }^{2}$

Hearing

Received mental health diagnosis in past 12 months? (overall $n=1119,13.56 \%$ )

Hearing impairment 224 (17.5\%) versus no hearing impairment $(n=895,12.9 \%)$

Received medical treatment for mental illness in past 12 months? (overall $n=1021,11.59 \%$ )

Hearing impairment $(n=233,16.7 \%)$ versus no hearing impairment $(n=788,10.7 \%)$

Received psychological therapy in past 12 months? (overall $n=236,2.97 \%$ )

Hearing impairment $(n=42,2.8 \%)$ versus no hearing impairment $(n=194,3.0 \%)$

Distance vision

Received mental health diagnosis in past 12 months?

Distance vision impairment $(n=118,27.7 \%)$ versus no distance vision impairment $(n=1001$, $12.8 \%)$

Received medical treatment for mental illness in past 12 months?

Distance vision impairment $(n=108,22.9 \%)$ versus no distance vision impairment $(n=913$,

$11.0 \%$

Received psychological therapy in past 12 months?

Distance vision impairment ( $n=28,6.9 \%$ ) versus no distance vision impairment ( $n=208,2.8 \%$ )

Near vision

Received mental health diagnosis in past 12 months?

Near vision impairment ( $n=212,22.9 \%)$ versus no near vision impairment ( $n=907,12.5 \%)$

Received medical treatment for mental illness in past 12 months?

Near vision impairment ( $n=195,20.0 \%)$ versus no near vision impairment $(n=826,10.6 \%)$

Received psychological therapy in past 12 months?

Near vision impairment ( $n=41,4.4 \%)$ versus no near vision impairment $(n=195,2.8 \%)$

\begin{tabular}{|c|c|c|c|}
\hline 1.44 (1.19-1.74) & $<0.001$ & $1.61(1.24-2.08)$ & $<0.001$ \\
\hline 1.68 (1.39-2.02) & $<0.001$ & $1.29(1.04-1.60)$ & 0.019 \\
\hline 0.95 (0.65-1.39) & 0.776 & $1.10(0.70-1.74)$ & 0.668 \\
\hline $2.61(1.99-3.41)$ & $<0.001$ & $1.65(1.14-2.39)$ & 0.009 \\
\hline $2.40(1.85-3.12)$ & $<0.001$ & $1.22(0.89-1.69)$ & 0.212 \\
\hline $2.61(1.59-4.28)$ & $<0.001$ & $1.51(0.83-2.77)$ & 0.177 \\
\hline $2.08(1.71-2.53)$ & $<0.001$ & $1.45(1.12-1.89)$ & 0.005 \\
\hline $2.11(1.73-2.57)$ & $<0.001$ & $1.21(0.96-1.53)$ & 0.110 \\
\hline $1.60(1.06-2.43)$ & 0.026 & $1.10(0.67-1.79)$ & 0.703 \\
\hline
\end{tabular}

a. Adjusted for age, gender, ethnicity, employment type, history of significant physical health condition, ever having smoked and total CIS-R score.

healthcare, ${ }^{34}$ and more than a quarter with hearing loss do not understand their diagnosis following a general practitioner appointment. ${ }^{1}$ Our finding may indicate that people with sensory impairment are more likely to be known to health professionals through the sensory impairment itself, leading to common mental illness being detected. There was, however, no strong evidence that they are more likely to receive treatment for common mental illness following its detection. It may be that milder mental illness that merits a 'watch and wait' strategy is being detected in people with sensory impairment. This is supported by the fact that in our descriptive sensitivity analysis, people with sensory impairment and a CIS-R score of 18 or more were no less likely to receive treatment (supplementary Table 1). It may, however, be the case that people with sensory impairment and milder common mental illness are receiving a diagnosis but not treatment even when it is appropriate.

\section{Strengths and limitations}

Strengths of our study include the use of a large nationally representative sample, separation of near and distance visual impairment and the assessment of multiple potential confounders and mediators of the relationship between sensory impairment and common mental illness.

There are also a number of limitations. First, causation cannot be inferred since the APMS data are cross-sectional and there is no means to determine the temporality of the data. This is particularly relevant to the mediation analysis. Although we have assumed that depression and anxiety do not directly cause sensory impairment, it could be that they reduce motivation to address medical causes of sensory impairment early on and facilitate its development. Stress and mental illness may even predispose to sensory impairment. ${ }^{35-37}$ Social isolation might also reduce opportunity to

Table 6 Mediation analysis: assessment of mediation of association of sensory impairment with Clinical Interview Schedule Revised (CIS-R) Score by Social Functioning Questionnaire (SFQ) score $^{\text {a }}$

\begin{tabular}{|c|c|c|c|c|}
\hline Analytic sample $(n=6934)$ & $\begin{array}{l}\text { Unadjusted mean difference in CIS-R score } \\
\text { in sensory impairment }(95 \% \mathrm{Cl})\end{array}$ & $P$ & $\begin{array}{l}\text { Adjusted mean difference in CIS-R score } \\
\text { in sensory impairment }(95 \% \mathrm{Cl})^{\mathrm{b}}\end{array}$ & $P$ \\
\hline \multicolumn{5}{|l|}{ Hearing impairment } \\
\hline Total effect of sensory impairment on CIS-R Score & $0.86(0.29$ to 1.43$)$ & 0.003 & $1.38(0.80$ to 1.96$)$ & $<0.001$ \\
\hline Indirect effect via SFQ score & $-0.09(-0.40$ to 0.22$)$ & 0.575 & 0.65 (0.36 to 0.95$)$ & $<0.001$ \\
\hline Direct effect of sensory impairment on CIS-R Score & $0.95(0.48$ to 1.42$)$ & $<0.001$ & $0.73(0.24$ to 1.22$)$ & 0.004 \\
\hline \multicolumn{5}{|l|}{ Distance vision impairment } \\
\hline Total effect of sensory impairment on CIS-R Score & 4.09 (2.96 to 5.22$)$ & $<0.001$ & 3.55 (2.45 to 4.65$)$ & $<0.001$ \\
\hline Indirect effect via SFQ score & $1.82(1.18$ to 2.46$)$ & $<0.001$ & 1.95 (1.33 to 2.56$)$ & $<0.001$ \\
\hline Direct effect of sensory impairment on CIS-R Score & $2.27(1.41$ to 3.14$)$ & $<0.001$ & $1.60(0.77$ to 2.44$)$ & $<0.001$ \\
\hline \multicolumn{5}{|l|}{ Near vision impairment } \\
\hline Total effect of sensory impairment on CIS-R Score & 3.13 (2.45 to 3.81$)$ & $<0.001$ & 2.97 (2.30 to 3.63$)$ & $<0.001$ \\
\hline Indirect effect via SFQ score & $1.25(0.87$ to 1.62$)$ & $<0.001$ & 1.49 (1.13 to 1.85$)$ & $<0.001$ \\
\hline Direct effect of sensory impairment on CIS-R Score & 1.88 (1.31 to 2.45$)$ & $<0.001$ & $1.47(0.93$ to 2.02$)$ & $<0.001$ \\
\hline
\end{tabular}


obtain help for sensory impairment. Hence, reverse causation cannot be ruled out in our study, and a longitudinal analysis is needed to confirm our findings.

The CIS-R, despite being a valid measure, gives an indication of symptomatology only and cannot be as accurate as a professional diagnostic interview in ascertaining the presence of common mental illness. Measurement of the exposure was by self-report only, although self-reported sensory impairment has been shown to be a reasonably accurate measure. ${ }^{38,39}$ Measurement of having received a diagnosis and treatment was also limited to self-report data. Some potential confounders were not measured, such as tinnitus. ${ }^{40}$ This might have led to an overestimation of the association.

The analyses exploring the treatment gap may have included too few participants in each group to have the power to detect a clinically significant effect. This is one possible reason that we found people with sensory impairment to be more likely to have received a diagnosis of mental illness but not treatment. Including people with hearing aids might have selected proportionately more people who are better able to seek healthcare into the exposed group, reducing the likelihood of finding a treatment gap. The data we have used in assessing receipt of diagnosis and treatment may also be prone to recall bias, as it depended on participants recounting events over the past year. ${ }^{18}$ Some of the participants would have been living with dementia; they may have had particular difficulties recalling diagnosis and treatment, but are at increased risk of experiencing anxiety and depression. ${ }^{41}$ This would be expected to artificially inflate the treatment gap for people with sensory impairment; however, this was not seen in our study.

The APMS only covers those living in private households and excludes groups such as prisoners and people in nursing homes. The older population who live in communal or institutional settings are more likely to have worse mental health and dementia than older people who live in private households. ${ }^{18,42}$ As a large proportion of the population with sensory impairment are older this may have led to a slight underestimation of the association between sensory impairment and CIS-R score. It has, however, been estimated that those not living in private households represent less than $2 \%$ of the UK population. ${ }^{18}$

It is also possible that people with sensory impairment may have been more prone to exclusion from the APMS than the general population. This may have led to an underestimate of the effect size if the most socially disadvantaged people with sensory impairment could not participate. We did not distinguish between degrees of impairment, whether impairment was well-corrected with aids or recently acquired and life-long impairments. The results between these groups could be different. ${ }^{29}$

\section{Implications}

Clinicians working with people with sensory impairments need to be alert to the possibility of comorbid mental illness so that timely interventions can be provided where appropriate. This is especially true in younger adults, for whom the association appears to be more pronounced. Treatment for clinically significant mental illness should be offered when it is detected, regardless of comorbidities, particularly given our finding that people with sensory impairment might be more likely to receive a diagnosis. Depression and anxiety should not be seen as inevitable or untreatable consequences of sensory impairment. Integrating mental and physical healthcare in sensory-impairment specific interventions has been shown to be effective in reducing the incidence of depressive disorders in a low vision clinic. ${ }^{43}$ There is also evidence that auditory rehabilitation helps people with hearing impairment to adapt to this condition. ${ }^{44}$ Our findings also highlight the importance of preventing and correcting sensory impairment, which is often possible, to preserve psychological well-being. ${ }^{45}$ Finally, clinicians should be aware of specialist mental health services for culturally deaf individuals.

It appears that further research into the mediators of common mental illness in people with sensory impairment is also required. Social functioning may be a potentially modifiable target for the prevention of mental illness in people with sensory impairment. Sensory impairment severe enough to interfere with social functioning in particular should alert clinicians to the need to consider the impact on the patient's mental health.

Natalie Shoham (D), Clinical Training Fellow, Division of Psychiatry, University College London, UK; Gemma Lewis, Research Associate in Epidemiology, Division of Psychiatry, University College London, UK; Sally McManus $\mathbb{D}$, Associate, National Centre for Social Research, UK; Claudia Cooper (D), Professor in Psychiatry of Older Age, Division of Psychiatry, University College London, UK

Correspondence: Natalie Shoham. Email: natalie.shoham.16@ucl.ac.uk

First received 1 Jul 2019, accepted 3 Oct 2019

\section{Funding}

Supported by the University College London Hospitals National Institute of Health Research Biomedical Research Centre.

\section{Acknowledgements}

We would like to thank NHS Digital for granting us permission to use the APMS data.

\section{Data availability}

The data that support the findings of this study are available from NHS Digital. Restrictions apply to the availability of these data.

\section{Supplementary material}

Supplementary material is available online at https://doi.org/10.1192/bjo.2019.81.

\section{References}

1 Action on Hearing Loss. Hearing Matters. Action on Hearing Loss, 2015 (https:// www.actiononhearingloss.org.uk/about-us/our-research-and-evidence/ research-reports/hearing-matters-report/).

2 Contrera KJ, Betz J, Deal J, Choi JS, Ayonayon HN, Harris T, et al. Association of hearing impairment and anxiety in older adults. J Aging Health 2017; 29: 172-84.

3 Jayakody DM, Almeida OP, Speelman CP, Bennett RJ, Moyle TC, Yiannos JM, et al. Association between speech and high-frequency hearing loss and depression, anxiety and stress in older adults. Maturitas 2018; 110: 86-91.

4 Han J, Lee H, Jung J, Park E-C. Effects of self-reported hearing or vision impairment on depressive symptoms: a population-based longitudinal study. Epidemiol Psychiatr Sci 2019; 28: 343-55.

5 Kim J-Y, Lee JW, Kim M, Kim MJ, Kim D-K. Association of idiopathic sudden sensorineural hearing loss with affective disorders. JAMA Otolaryngol Head Neck Surg 2018; 144: 614-21.

6 Cimarolli VR, Jopp DS, Boerner K, Minahan J. Depressive symptoms in the oldest-old: the role of sensory impairments. Arch Gerontol Geriatr 2018; 78: 249-54.

7 Stam M, Smit JH, Twisk JW, Lemke U, Smits C, Festen JM, et al. Change in psychosocial health status over 5 years in relation to adults' hearing ability in noise. Ear Hear 2016; 37: 680-9.

8 West JS. Hearing impairment, social support, and depressive symptoms among US adults: a test of the stress process paradigm. Soc Sci Med 2017; 192: 94-101.

9 McManus S, Lord C. Circumstances of People with Sight Loss: Secondary Analysis of Understanding Society and the Life Opportunities Survey. Natcen Report and RNIB, 2012.

10 Cosh S, Von Hanno T, Helmer C, Bertelsen G, Delcourt C, Schirmer H, et al. The association amongst visual, hearing, and dual sensory loss with depression and anxiety over 6 years: the Tromsø Study. Int J Geriatr Psychiatry 2018; 33: 598-605. 
11 Carrière I, Delcourt C, Daien V, Pérès K, Féart C, Berr C, et al. A prospective study of the bi-directional association between vision loss and depression in the elderly. J Affect Disord 2013; 151: 164-70.

12 Hsu W-T, Hsu C-C, Wen M-H, Lin H-C, Tsai H-T, Su P, et al. Increased risk of depression in patients with acquired sensory hearing loss: a 12-year followup study. Medicine 2016; 95: e5312.

13 simning A, Fox ML, Barnett SL, Sorensen S, Conwell Y. Depressive and anxiety symptoms in older adults with auditory, vision, and dual sensory impairment. J Aging Health 2019: 31:1353-75.

14 Levine J. Primary care for deaf people with mental health problems. Br J Nurs 2014; 23: 459-63.

15 Fellinger J, Holzinger D, Pollard R. Mental health of deaf people. Lancet 2012; 379: $1037-44$.

16 Pandhi N, Schumacher JR, Barnett S, Smith MA. Hearing loss and older adults perceptions of access to care. J Community Health 2011; 36: 748-55.

17 Sharts-Hopko NC, Smeltzer S, Ott BB, Zimmerman V, Duffin J. Healthcare experiences of women with visual impairment. Clin Nurse Spec 2010; 24: 149-53.

18 McManus S, Bebbington P, Jenkins R, Brugha T. NHS Digital. Mental Health and Wellbeing in England: Adult Psychiatric Morbidity Survey 2014. NHS Digital, 2016.

19 Lewis G, Pelosi AJ, Araya R, Dunn G. Measuring psychiatric disorder in the community: a standardized assessment for use by lay interviewers. Psychol Med 1992; 22: 465-86.

20 Nelson HE, Willison J. National Adult Reading Test (NART). Nfer-Nelson Windsor, 1991.

21 Saunders JB, Aasland OG, Babor TF, de la Puente JR, Grant M. Development of the Alcohol Use Disorders Screening Test (AUDIT). WHO collaborative project on early detection of persons with harmful alcohol consumption. II. Addiction 1993; 88: 791-804.

22 Tyrer $\mathrm{P}$, Nur U, Crawford M, Karlsen S, MacLean C, Rao B, et al. The Social Functioning Questionnaire: a rapid and robust measure of perceived functioning. Int J SOC Psychiatry 2005; 51: 265-75.

23 Stata Corp. Stata Statistical Software: Release 14. Stata Corp LP, 2015

24 Garin N, Olaya B, Lara E, Moneta MV, Miret M, Ayuso-Mateos JL, et al. Visual impairment and multimorbidity in a representative sample of the Spanish population. BMC Public Health 2014; 14: 815

25 Huang C-Q, Dong B-R, Lu Z-C, Yue J-R, Liu Q-X. Chronic diseases and risk for depression in old age: a meta-analysis of published literature. Age Res Rev 2010; 9: 131-41.

26 Shoham N, Lewis G, Favarato G, Cooper C. Prevalence of anxiety disorders and symptoms in people with hearing impairment: a systematic review. Soc Psychiatry Psychiatr Epidemiol 2019; 54: 649-60.

27 Schuster AK, Tesarz J, Rezapour J, Beutel ME, Bertram B, Pfeiffer N. Visual impairment is associated with Depressive symptoms - results from the nationwide German Degs1 study. Front Psychiatry 2018; 9: 114.

28 Bernabei V, Morini V, Moretti F, Marchiori A, Ferrari B, Dalmonte E, et al. Vision and hearing impairments are associated with depressive-anxiety syndrome in Italian elderly. Aging Ment Health 2011; 15: 467-74.

29 Du Feu M, Fergusson K. Sensory impairment and mental health. Adv Psychiatr Treat 2003; 9: 95-103.
30 Rutherford BR, Brewster K, Golub JS, Kim AH, Roose SP. Sensation and psychiatry: linking age-related hearing loss to late-life depression and cognitive decline. Am J Psychiatry 2017; 175: 215-24.

31 Dawes P, Emsley R, Cruickshanks KJ, Moore DR, Fortnum H, EdmondsonJones $\mathrm{M}$, et al. Hearing loss and cognition: the role of hearing AIDS, social isolation and depression. PLOS One 2015; 10: e0119616.

32 Palmer AD, Carder PC, White DL, Saunders G, Woo H, Graville DJ, et al. The impact of communication impairments on the social relationships of older adults: pathways to psychological well-being. J Speech Lang Hear Res 2019; 62: 1-21.

33 Hodge S, Eccles F. Loneliness, Social Isolation and Sight Loss: a Literature Review Conducted for Thomas Pocklington Trust. Lancaster University, 2013.

34 Leigh IW, Pollard RQ. Mental health and deaf adults. In The Oxford Handbook of DeafStudies, Language, and Education, Volume 1, Second Edition (2 ed.) (eds M Marschark, PE Spencer): 214-26. Oxford University Press, 2011

35 Zheng DD, Bokman CL, Lam BL, Christ SL, Swenor BK, West SK, et al. Longitudinal relationships between visual acuity and severe depressive symptoms in older adults: the Salisbury Eye Evaluation study. Aging Ment Health 2016; 20: 295-302.

36 Sabel BA, Wang J, Cárdenas-Morales L, Faiq M, Heim C. Mental stress as consequence and cause of vision loss: the dawn of psychosomatic ophthalmology for preventive and personalized medicine. EPMA J 2018; 9:133-60.

37 Lin C, Lin Y, Liu C, Weng S, Lin C, Lin B. Increased risk of sudden sensorineural hearing loss in patients with depressive disorders: population-based cohort study. J Laryngol Otol 2016; 130: 42-9.

38 Sindhusake $D$, Mitchell $P$, Smith $W$, Golding $M$, Newall $P$, Hartley $D$, et al. Validation of self-reported hearing loss. The Blue Mountains hearing study. Int J Epidemiol 2001; 30: 1371-8.

39 Whillans J, Nazroo J. Assessment of visual impairment: the relationship between self-reported vision and 'gold-standard'measured visual acuity. Br J Visual Impairment 2014; 32: 236-48.

40 Matthews L. Hearing Loss, Tinnitus and Mental Health. A Literature Review. Action on Hearing LOSS, 2013.

41 Jorm AF. History of depression as a risk factor for dementia: an updated review. Aust N Z J Psychiatry 2001; 35: 776-81.

42 Livingston G, Barber J, Marston L, Rapaport P, Livingston D, Cousins S, et al. Prevalence of and associations with agitation in residents with dementia living in care homes: MARQUE cross-sectional study. BJPsych Open 2017; 3: 171-8.

43 Rovner BW, Casten RJ, Hegel MT, Massof RW, Leiby BE, Ho AC, et al. Low vision depression prevention trial in age-related macular degeneration: a randomized clinical trial. Ophthalmology 2014; 121: 2204-11.

44 Blazer DG, Tucci DL. Hearing loss and psychiatric disorders: a review. Psychol Med 2019; 49: 891-7

45 Rishi P, Rishi E, Maitray A, Agarwal A, Nair S, Gopalakrishnan S. Hospital anxiety and depression scale assessment of 100 patients before and after using low vision care: A prospective study in a tertiary eye-care setting. Indian J Ophthalmol 2017; 65: 1203.

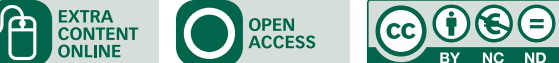

